\title{
Effect of Mercury Pollution on the Urban Environment and Human Health
}

\author{
Salameh Azimi ${ }^{1, *}$, Mohammadreza Sadeghi Moghaddam² \\ ${ }^{1}$ Department of Chemistry, Takestan Branch, Islamic Azad University, Takestan. Iran \\ ${ }^{2}$ Department of Architecture, and urban planning Islamic Azad University,Qazvin Branch,Qazvin, Iran \\ *Corresponding Author: salamehazimi@gmail.com
}

Copyright $(2013$ Horizon Research Publishing All rights reserved.

\begin{abstract}
As developing countries to become industrialized and urbanized, heavy metal pollution is likely to reach disturbing levels. These countries should learn from the mistakes of the developed nations and recognize that rapid deterioration of the environment can occur. There is a lack of data on the nature and extent of metal pollution either at local and regional level, particularly to assist in the understanding of metal cycling in the environment. Although most countries recognize the need to combat pollution, environmental, controls are either nonexistence or inadequate. So in this article we emphasized on one of the most important environment pollutant $(\mathrm{Hg})$ and effect of mercury on the human health and at the end of the article some important and easy ways for preventing mercury hazards will be recommended.
\end{abstract}

Keywords Mercury, Heavy Metal, Environment, Urbanized, Human Health

\section{Introduction}

Mercury is one of the most toxic elements and a threat to wild life because it accumulates and magnifies to unsafe levels in aquatic food chains [1], it cannot be removed and is rapidly transformed by microorganisms into organic compounds that tend to bioaccumulate and biomagnify in animals[2]. All mercury species is toxic, with organic mercury compounds generally being more toxic than inorganic species [3]. Since about $8090 \%$ of all the mercury present in fish is generally assumed to be $\mathrm{MeHg}$ [4] Because of its high bioaccumulation, mercury concentrations escalate up the food chain and, e.g. predatory fish can have up to 106 times higher mercury concentrations than the ambient water [5] the organic form is most toxic as it passes the blood brain barrier owing to its lipid solubility. So the primary route of exposure to $\mathrm{MeHg}$ for humans is consumption of fish [6].

Since the beginning of the industry, anthropogenic activities like increased mining, high rate of fossil-fuel burning, widespread use of raw materials containing mercury in the industries are some important contributors of mercury to the environment [7]. The growing awareness of environmental of mercury pollution and toxicity necessitates the recognizing and determining of its very low concentration in a variety of samples, especially water. The allowed mercury level set by World Health Organization (WHO) for drinking water is $1 \mu \mathrm{gL}^{-1}$ [8]. Mercury is also considered by the environmental Protection Agency (EPA) as a highly dangerous element because of its accumulative and persistent character in the environment and biota. The damage has vast implications with human beings at the top of food chain getting worst of the deal owing to biomagnifications [9]. Over the last three decades there has been increasing global concern over the public health impacts attributed to environmental pollution, in particular, the global burden of disease. WHO estimates that about a quarter of the disease facing mankind today occur due to prolonged exposure to environmental pollution [10]. The amount of $\mathrm{Hg}$ mobilize and released in to the environment has increased since the beginning of the industrial age. $\mathrm{Hg}$ pollution is primarily due to human activities. Most of the world's industries are located in urban settings and a large proportion of $\mathrm{Hg}$ emissions from industries are deposited locally.

It is well known that environmental pollution is a product of urbanization and technology and other attendant factors of pollution density, industrialization and mechanization that serve to provide the necessities of the population [11].

Mercury and its compounds are currently used in a number of countries, especially in industrial countries such as Iran, for various purposes, mercury is applied in several different aspects of industries such as Batteries [12-14], Measuring and control equipment: medical and other thermometers, blood pressure thermometers[15], blood pressure gauges, manometers, pressure valves, gyroscopes, Lighthouses (marine use; for stabilizing lenses), Discharge lamps like fluorescent lamps, Laboratory chemicals, electrodes and apparatus for analysis, Color photograph paper, Slimicides for paper production, Airbag activators and anti-lock braking system (ABS) mechanisms in cars, Explosives, fireworks, Color photograph paper, 
Chloro-alkali production (chlorine and caustic soda), Dental amalgam, Pharmaceuticals: preservatives in vaccines and eye drops, disinfectants; skin lightening creams and soaps; herbal medicine, "folk" medicine, "street pharmacies", Cosmetics: biocides in eye cosmetics, Arm and leg bands (e.g., for "tennis elbow"), Religious ceremonies "superstitious" activities, Pesticides, especially for seed dressing.

\section{Environmental Pollution}

The majority of mercury emissions to air are in the form of gaseous elemental mercury, which can be transported globally to regions far from the emissions source. The remaining emissions are in the form of gaseous inorganic ionic mercury forms (such as mercuric chloride) or bound to emitted particles. These forms have a shorter atmospheric lifetime and will deposit to land or water bodies within roughly 100 to 1,000 kilometres of their source. The ocean currents are also media for long range mercury transport.

In the last decades $\mathrm{Hg}$ levels have been reported in urban atmosphere, urban dust [16-18], and suburban soils [19] and the distribution of $\mathrm{Hg}$ in urban soils and the differences of $\mathrm{Hg}$ concentration in of land use were determined by $\mathrm{Xi}$ Chen and his co-workers [20] Heavy metals such as mercury may be released in to the environment from metal smelting and refining industries, scrap metal, plastic industries, burning of waste containing these elements and etc [21]. Mercury can affect on some different parts of the environment such as:

\subsection{Air Pollution}

Metallic, or elemental mercury, is a liquid at room temperature and like any other liquid it evaporates into the air, where it can be inhaled. Very small amounts of metallic mercury, released into an enclosed space, can raise air concentrations of mercury to levels that may be harmful to health. The longer people breathe the contaminated air, the greater the risk to their health. In addition, metallic mercury and its vapors are extremely difficult to remove from clothes, furniture, carpet, and other porous items.

Some mercury sources in air are household products, including thermostats, glass thermometers, barometers, and switches in large appliances (e.g., gas-fired stoves). Barometers, however, have small openings in order to measure air pressure. Mercury vapors may be slowly released from them without breakage. Fluorescent bulbs contain a small amount of mercury vapor and a larger amount of mercury in a powder or dust form, whether accidental or intentional, spills of metallic mercury in a home or apartment [22].

\subsection{Water Pollution}

Water pollution referred to the additional to the water of an excess of material that is harmful to humans, animals and fishes [23]. The materials found in water and considered toxic to fish and other sea animals in one way or another can be recognized into oxygen debilitating materials, toxic gases, toxic organic compounds and pesticides, etc. The concentration of freshwater with a wide range of pollutants has become a matter of concern over the last few decades [24]. The natural aquatic systems may extensively be contaminated with heavy metals released from domestic, industrial, mining and other man-made activities [25].

\subsection{Mercury and Human Health}

Mercury is in widespread use in health care facilities. Thermometers and sphygmomanometers contain mercury and so do many medical batteries, fluorescent lamps and electrical switches. Mercury compounds are also in preservatives, fixatives and reagents used extensively in hospital laboratories. In soviet time there were regulations on all discharged mercury containing products, which had to be recycled in an appropriate plant.

\subsubsection{Mercury in Medicine}

Thousands of parents have reported biological and neurodevelopment changes in their children directly following administration of mercury-containing vaccines with a broad range of symptoms, including sudden onset of shyness, GI distress, loss of motor skill function, allergies, the inability to speak, tremors and autonomic disturbances, all which mimic those associated with mercury poisoning. Mercury has been shown to induce a number of immunological and neurotoxic changes [26].

Dr. David Baskin at the department of Neurosurgery at Baylor College of Medicine demonstrated 1) thimerosal in micormolar concentrations rapidly induce membrane and DNA damage 2) decreases mitochondrial membrane potential, 3) causes the release of both cytochrome clease of both cytochromec (AIF) from the mitochondria, 4) increases intracellular levels of reactive oxygen species (ROS) 5) initiate caspase-3 dependent apoptosis in human neurons and fibroblasts 6) reduces intracellular concentration of glutathione (GSH). Glutathione is an anti-oxidant that protects cells from oxidative stress-induced apoptosis. “,.”[27] Dr. J. Curtis Pendergrass and Dr. Boyd Haley confirm this stating, "Pure thimerosal was toxic at the low nanomolar level - an extremely low concentration, about 10,000 times less than the thimerosal concentration found in most vaccines. These results leave little doubt about thimerosal being the toxic agent in the vaccines."[28].

\subsubsection{Nervous System}

The nervous system is very sensitive to all forms of mercury. Methyl mercury and metallic mercury vapors are more harmful than other forms, because more mercury in these forms reaches the brain. Exposure to high levels of metallic, inorganic, or organic mercury can permanently damage the brain, kidneys, and developing fetus. Effects on 
brain functioning may result in irritability, shyness, tremors, changes in vision or hearing, and memory problems [29].

Low concentration of some metals, including mercury can induce the major constituent of intracellular protein inclusions in dopaminergic neurons and lead some rode generative disease such as Alzaimer's and Parkinson's diseases [30].

Damage to the nerves of the arms and legs (polyneoropathy) has been reported in employees with high exposures. Reduced sensation and strength in the arms and legs, muscle cramps and decreased nerve conduction have been observed.

Other researchers reported that the developing brain is highly sensitive to methyl-Hg. These researchers undertook a study to determine whether an environmental toxicant could also impact brain development with rapid (6-7 h) effects on DNA synthesis and cell cycle machinery in neuronal precursors. In vivo studies in newborn rat hippocampus and cerebellum, two regions of postnatal neurogenesis, were followed by an in vitro analysis of cortical and cerebellar cells used as surrogates for the brain's developmental status. The in vitro analyses performed focused on the proteins that regulate the G1/S transition. In post-natal day 7 pups, a single subcutaneous injection of methyl-Hg $(3 \mu \mathrm{g} / \mathrm{g})$ acutely $(7 \mathrm{~h})$ decreased DNA synthesis in the hippocampus by 40 percent and produced long term (2 wk) reductions in total cell number, estimated by DNA quantification. These authors estimated that the rat brain $\mathrm{Hg}$ levels which induced these significant adverse effects, were about 200-300 parts-per-billion [31].

Seven day old rats received a single injection of methyl-Hg, $5 \mu \mathrm{g} / \mathrm{g}$ body weights. This resulted in an estimated rat brain $\mathrm{Hg}$ concentration of about 500 parts perbillion. Methyl-Hg inhibited DNA synthesis by 44 percent and reduced levels of cycling $\mathrm{D}_{1}, \mathrm{D}_{3}$, and $\mathrm{E}$ at $24 \mathrm{~h}$ in the hippocampus, but not in the cerebellum.

Toxicity was highly associated with caspase-dependent programmed cell death. The methyl-Hg treatments resulted in reductions in hippocampal size (21per cent) and cell numbers 2 weeks later, especially in the granule cell layer (16per cent) and hilus (50per cent) of the dentate gyrus defined stereologically. Collectively, these findings suggest that neurons may be particularly vulnerable to $\mathrm{Hg}$ exposure. It was also postulated that the methyl-Hg exposure in the rats induced effects on cell migration as well as axon and synapse formation. In addition, these researchers described how, in preliminary studies, they found that a greater than 15 - fold lower dose of methyl-Hg $(0.3 \mu \mathrm{g} / \mathrm{g}$ body weight $)$ elicited a 3 -fold increase in the number of caspase 3-positive cells in the treated animals as compared to the controls. Overall, their results indicated that exposure to one dose of methyl-Hg during the perinatal period acutely induced apoptotic cell death, which, in turn, led to later deficits in hipocampal structure and function [32].

\subsubsection{Renal System}

Kidneys accumulate highest levels of mercury compared to brain and liver [33]. Renal toxicity of mercuric chloride is well documented in literature. When urine mercury levels are low to moderate, the results are inconclusive with no effects being reported in some studies and mild effects reported in others.

\subsubsection{Dental Amalgam}

Since a study funded by the American Dental Association (ADA) estimated that dental offices discharge approximately 6.5 tons of mercury per year to sewage treatment systems nationwide[34], it represents the second largest use of mercury after the industrial use of mercury for chlorine production, when mercury is released into the environment from whatever source; it is highly mobile, cycling between the atmosphere and the earth's surface, where it is deposited in soils, water bodies and bottom sediments. In soil and water, microorganisms convert elemental mercury into the more toxic methyl mercury which aquatic plants and animals ingest or absorb. Methyl mercury has the capacity to collect in organisms (bioaccumulate) and to 'biomagnify' as the concentrations increase up each level of the food chain, especially in the aquatic food chain [35].

Pre-concentration, separation and detection

Total dissolved mercury determination

The most common technique used to monitor total mercury in natural waters is cold vapour atomic fluorescence spectrometry (CVAFS). As a pre-treatment step, natural water samples are digested to transform all mercury species to "reducible" mercury (free inorganic $\mathrm{Hg}$ II ions) by addition of a strong oxidant, e.g. bromine chloride, permanganate, or UV light. After pre-reduction of excess oxidant, $\mathrm{Hg}$ II is reduced to elemental $\mathrm{Hg}^{0}$ by, e.g. Tin (II) chloride or sodium borohydride, which is then purged out of the reaction solution by an inert carrier gas. The $\mathrm{Hg}^{0}$ vapour, called "cold vapour" (CV), is then either transported directly to the detection cell or pre-concentrated on a gold trap by formation of an amalgam. This amalgamation procedure was first described for the pre-concentration of mercury from air samples and first used for water samples with CV generation in 1979 by Fitzgerald and Gill [36]. Subsequent heating of the gold trap releases the preconcentrated mercury which is then transported to the detection cell where mercury resonance fluorescence is measured at a wavelength of 253.7 $\mathrm{nm}$. Detection limits of $\mathrm{pg} \mathrm{Hg} \mathrm{\textrm {L } ^ { - 1 }}$ can be achieved with CVAFS depending mainly on the purity of the reagents and the inert gas used as well as on the cleanliness of the working procedures [37]. Possible $\mathrm{Hg}$ contamination of the inert gas may be removed by application of suitable gas scrubbing procedures. $\mathrm{CV}$ generation can be performed batch-wise or in a flow injection (FI) system. Integrated FI-CV systems with or without in-line precious metal traps - coupled to $\mathrm{Hg}$ detector are now commercially available.

The general CVAFS procedure described above for total mercury determination in natural waters is recommended by regulatory bodies such as the EPA (method 1631) [38] and the EU (EN 13506) [39]. This method has considerable drawbacks however, particularly the complex and 
time-consuming procedures involved. In order to simplify the procedure and lower the contamination risk during analysis, methods have been developed that integrate oxidative pre-treatment within an automated FI procedure [40-42]. These FI-CVAFS systems shorten sample analysis time lower the contamination risk because a closed system is used for sample pre-treatment and are typically more reproducible than the manual procedure. However, the very extensive cleaning procedures required for the reagents used for oxidative digestion, pre-reduction of oxidant excess and the reduction of $\mathrm{Hg}$ II to $\mathrm{Hg}^{0}$ mean that the method is still labor-intensive. In addition, only rigorous cleaning procedures allow low blank levels, and hence suitable sensitivity, to be achieved. In order to overcome these limitations alternative strategies for total mercury determination, especially after in situ monitoring are still required. In this context the use of a high-intensity ultrasound (US) field in combination with CV generation is one strategy that was first reported by Capelo et al. [43]. It is important to distinguish between the application of US for sample pre-treatment (i.e. conversion of mercury species into reducible $\mathrm{Hg} 2+$ ) by localised heating and radical-based attack of $\mathrm{Hg}$ species followed by chemical $\mathrm{CV}$ generation $[43,44]$ and the use of US for CV generation itself without reducing reagents, i.e. US-CV $[45,46]$. Methods for both strategies, followed by amalgamation pre-concentration, have been successfully applied to the determination of total mercury in estuarine [44], lake [45], river [46] and waters. Ribeiro et al. [47] reported that limits of detection were better for the US probe compared with chemical CV generation by tin (II) chloride, because the procedural blank obtained was five-fold lower than that for the chemical CV generation approach. Beside the combination of US-CV with amalgamation pre-concentration, the use of "in-atomizer" trapping in graphite furnace AAS after US-CV has been successfully applied to the determination of $\mathrm{Hg}$ in natural waters [48].

Another reagent-free method with high sensitivity (detection limit $80 \mathrm{pg} \mathrm{L}^{-1}$ ) uses nano-gold collectors for the decomposition and pre-concentration of $\mathrm{Hg}$ species directly from natural waters $[49,50]$. In comparison with other SPME approaches this method benefits from the catalytic activity of nano-gold and therefore requires neither complexation and decomposition reagents for efficient adsorption of $\mathrm{Hg}$ species nor any eluent, since desorption from the nano-gold collector can be performed thermally. Fig. 3 shows the FI manifolds for reagent-free on-line determination methods for total mercury by US-CVAAS [51] and SPME-AFS [52], respectively.

Atomic absorption spectroscopy (AAS) is the most frequently used technique for measuring mercury concentration, but the more sensitive atomic fluorescence spectroscopy (AFS) technique is becoming increasingly important. Mercury must be present as $\mathrm{Hg}^{0}$ (g) to be determined with AAS or AFS. Cold-vapor (CV) methods using reductants [53], such as $\mathrm{SnCl}_{2}$ or $\mathrm{NaBH}_{4}$, for converting ionic mercury (II) in solution to $\mathrm{Hg}^{0}$ (g) are most commonly used. The liberated $\mathrm{Hg}^{0}(\mathrm{~g})$ is entrained in an inert gas stream and then transferred directly into the absorption cell of an atomic absorption or fluorescence spectrometer. Although several on-line instruments capable of directly analyzing $\mathrm{Hg}^{0}(\mathrm{~g})$ in flue gas are being developed, most CVAAS and CVAFS methods require the sample to be in solution and are therefore suitable for the determination of mercury captured in impinge solutions. Solid samples can also be analyzed following dissolution. The chemical digestion of solid samples is based on the use of acid mixtures in microwave pressure relief vessels or polytetrafluoroethylene crucibles sealed in a steel or aluminum casing. The fundamental principles and applications of CVAAS and CVAFS have been described in many textbooks, including Robinson [54], Slavin [55], and Price [56] and in review papers by Ure [57] and Morita et al. [58]. The detection limit for mercury by CVAAS generally ranges from 0.02 to $0.2 \mathrm{ng} / \mathrm{ml}$, depending on the type of CVAAS instrument used [59] Standard procedures for CVAAS include Swedish standard SS 028423 [60], Method 303F [61], EPA Method 245.1[62], and EPA SW-846 7470 [63]. For the ICR, several methods were commonly used to analyze for mercury in coal, as shown in Table 1. Based on the results of a round-robin study done in conjunction with the recent ICR, the most promising methods for mercury determination in coal are Methods 1, 2, and 5 [64, 65]. Low mercury recoveries were reported for American Society for Testing and Materials (ASTM) D3684, suggesting that ash content and heating value may influence the accuracy of this method. Difficulty in reproducibility and a higher degree of variability occurred when the methods were used on coals with mercury concentrations lower than $0.060 \mathrm{ppm}$ [66]. Methods 2 and 5 have a slightly lower level of quantitation of about $0.030 \mathrm{ppm}[64,65]$. Instrumental neutral activation analysis is a nondestructive technique ideally suited for directly analyzing for mercury in solids [67 -69].

The technique is based on irradiation of a sample with a flux of neutrons followed by a cooling period and then measurement of the gamma rays emitted by the resulting radionuclide activation products [70]. The irradiation of mercury by neutrons activates ${ }^{196} \mathrm{Hg}$ to ${ }^{197} \mathrm{Hg}$ and ${ }^{202} \mathrm{Hg}$ to ${ }^{203} \mathrm{Hg}$. This radionuclide activation products decay with the emission of a $7.33-\mathrm{keV}$ gamma ray and by beta decay with the emission of a $279.2-\mathrm{keV}$ gamma ray, respectively. The emitted gamma rays are detected and separated according to their energies using a germanium detector coupled to a multichannel analyzer. The resulting gamma ray spectrum is compared and fitted to standard reference spectra to determine mercury concentration. The direct analysis of mercury minimizes contamination and errors introduced during sample preparation.

\subsection{Production and Disposal of Electrical and Electronic Products}

The EE manufacturing industry has been one of the largest users of $\mathrm{Hg}$ in the world for at least two decades. Nonetheless, it has received little scientific attention as compared to other 
major Hg users, such as chlor-alkali plants and gold mining. Limited scientific information concerning the quantity of global and regional $\mathrm{Hg}$ consumption by the industry was generated until recently. A report prepared by Silicon Valley Toxics Coalition (SVTC) suggested that $22 \%$ of the world's annual consumption of $\mathrm{Hg}$ was used in electronics [71].

According to Electronic Industries Alliance [72], $\mathrm{Hg}$ can be found in at least 26 categories of EE devices, including electrical lighting, switching devices, control instruments, thermostats, devices with florescence lamps in LCDs (e.g. laptop/notebook computers, mobile phones, flat panel LCD display TVs and monitors), and semiconductors [73-75]. Hg contents in laptop/notebook computers, flat panel LCD display TVs, multimedia monitors and LCD projector TVs are among the highest. A laptop/notebook computer or a flat panel (LCD) display monitor can have up to $50 \mathrm{mg} \mathrm{Hg}$, while as much as $100 \mathrm{mg} \mathrm{Hg}$ can be found in a multimedia monitor or an LCD projector TV [76]. Even though there has been a reduction in $\mathrm{Hg}$ content in some electronic products, the reduction may be counteracted by the increasing popularity of some Hg-containing EE devices [77-79] For instance, flat panel LCD monitors and flat panel LCD TVs are increasingly popular, gradually replacing traditional monitors and TVs with cathode ray tubes. It is projected that 14 million units of LCD TVs will be sold by 2006, a significant increase compared to less than 300,000 LCD TVs sold in 2001 [80].

\section{Measures to Avoid Mercury Pollution}

There are many convenient, inexpensive, yet very effective steps that consumers can take to prevent mercury from contaminating our children and our lakes, rivers, fish and wildlife. First and foremost, do not buy products that contain mercury. Thermometers and thermostats are the two most obvious consumer products for which mercury-free alternatives exist and it's so valuable to study for measures to avoid mercury emissions and related pollutions. Since the main sources of emitted mercury into the environment are two groups intentionally and not intentionally sources therefore our measures will be divided in these two groups.

Methyl mercury can carry out harmful effects on the reproductive, respiratory, and nervous system of human. Moreover, mercury is known as the most toxic heavy metal in nature. Fish and seafood consumption is the major $\mathrm{MeHg}$ exposure route for human.

Several kinds of method have been applied for determining mercury levels in different sea foods. The results show that the mercury pollution in Anzali pond is more than other places in Iran. In this study, the mercury content in some different kinds of fish were compared with each other by statistical calculations and the results showed there's a significance different between mercury determination by different analytical methods.

For the comparison of more than two sets of data, analysis of variance (ANOVA) is often used. For example, ANOVA is sometimes used to determine if results from some analysts are significantly different.

The Student's t-test and ANOVA are statistical tests for a 'zero-difference' hypothesis. Therefore, when the t-test or ANOVA are used to compare two sets of results, the following statistical question is asked: is it likely that no difference exists between two sets of results?

Therefore, zero-difference hypothesis tests should only be used if one wants to show that results from two methods are different. If one wants to determine equivalence, a more appropriate statistical question to ask is perhaps: is there an unacceptable difference between two sets of results?

The purpose of the present work was to analysis the mercury content of some fruits and vegetables by statistical methods.

Mercury concentration was determined by A.Esmaeili Sari and his co-workers [81] and mercury content means of fish are shown in Figure. 1, since high methyl mercury concentration in some kinds of fish in the north of Iran, it causes some serious problems especially for pregnant women. The researchers analyzed the mercury content of fish in 2 different days and each day the examined two series of each kind of fish then the means were presented for each series.

\begin{tabular}{|c|c|}
\hline Fish & Mercury concentration(mg/L) \\
\hline \multirow{2}{*}{ Sefid kuli } & $0.04,0.043$ \\
& $0.25,0.25$ \\
\hline \multirow{2}{*}{ Sorkh baleh } & $0.04,0.032$ \\
& $0.23,0.23$ \\
\hline \multirow{2}{*}{ Gambozia } & $0.04,0.056$ \\
& $0.32,0.3$ \\
\hline \multirow{2}{*}{ Kafal talaye } & $0.04,0.06$ \\
& $0.32,0.34$ \\
\hline \multirow{2}{*}{ Siah kuli } & $0.1,0.15$ \\
& $0.55,0.43$ \\
\hline \multirow{2}{*}{ Mahi sefid } & $0.12,0.24$ \\
& $0.84,0.82$ \\
\hline
\end{tabular}

Comparing the two different analyses by Anova Test:

\begin{tabular}{|c|c|c|c|}
\hline Fish group & $\begin{array}{c}\text { conc. } \\
(\mathrm{mg} / \mathrm{L})\end{array}$ & $\mathrm{Ti}$ & $\mathrm{Ti}^{2}$ \\
\hline $\begin{array}{c}\text { Mahi sefid } \\
\text { group1 }\end{array}$ & $0.12,0.24$ & 0.36 & 0.1296 \\
\hline $\begin{array}{c}\text { Mahi sefid } \\
\text { group 2 }\end{array}$ & $0.84,0.82$ & 1.66 & 2.7556 \\
\hline & & $\begin{array}{c}\mathrm{T}={ }^{2} .02 \\
\mathrm{~T}^{2}=4.0804\end{array}$ & $\Sigma \mathrm{Ti}^{2}=2.8852$ \\
\hline
\end{tabular}

$\mathrm{n}=2, \mathrm{~h}=2, \mathrm{~N}=4$

$\mathrm{SSR}=\Sigma \mathrm{Ti} 2 / \mathrm{n}-\mathrm{T} 2 / \mathrm{N}=0.4225$

$\mathrm{SST}=\Sigma \mathrm{xi} 2-\mathrm{T} 2 / \mathrm{N}=0.4299$

$\mathrm{SSE}=\mathrm{SST}-\mathrm{SSR} / \mathrm{N}-\mathrm{h}=0.0037$

$\mathrm{F}=\mathrm{SSR} / \mathrm{SSE}=114.189$, Fcritical $=18.51$

Figure 1. mercury concentration means of some kinds of Caspian lake fish in Iran.

Other groups of fish were analyzed by anova test and calculated $\mathrm{F}$ for sefid kuli, sorkh baleh, gambozia, kafal talaei, siah kuli and mahi sefid are, 196.81, 87.97, 136, 103.6, $29.88,114.189$ respectively. By comparing with critical F, we can conclude that none of them are similar to each other 
and there's a significance differences between them.

\subsection{Measures against Pollution from Intentionally Use of $\mathrm{Hg}^{2+}$}

$\mathrm{Hg}$ used in dentistry and industry are two important examples of intentionally use of $\mathrm{Hg}$, pollution caused by continued intentionally use of $\mathrm{Hg}$ is easy to stop because, not using $\mathrm{Hg}$ will terminate $\mathrm{Hg}$ emission and pollution. Historical, intentional use of $\mathrm{Hg}$ has resulted in large stockpiles of $\mathrm{Hg}$ in society, which will result in continued pollution even after a total stop of using $\mathrm{Hg}$. One of the largest polluter of intentionally use of $\mathrm{Hg}$ is mercury electrodes. The $\mathrm{Hg}$ cells in Sweden are due to be replaced by $\mathrm{Hg}$ free technology and accompanied by a safe disposal of their $\mathrm{Hg}$ stock. Pollution from mercury in dental filling is another important intentionally uses of $\mathrm{Hg}$, large amount of $\mathrm{Hg}$ are used in electrical equipments, chemistry laboratories especially in most industrialized countries. Technologies for reducing the amount of $\mathrm{Hg}$ and replacing it are so costly and difficult. Dentists are one of the largest identified sources for mercury emission; therefore an outreach program for dentists would involve the development of informational materials describing best management practices for dealing with amalgam, amalgam waste and spills from amalgam preparation. A paper should have a short, straightforward title directed at general readers in no more than 20 words.

\subsubsection{Important Information for Dentists Includes}

1. Proper ways to clean amalgam traps and vacuum filters to avoid releasing the trapped mercury to the sewer system.

2. Proper storage of waste amalgam (used and unused) without the use of water.

3. Waste amalgam disposal methods with an emphasis on recycling (and a list of mercury recyclers in the area).

4. Mercury spill prevention and spill cleanup methods.

Dentists could be encouraged to reduce or eliminate the use of mercury amalgam and to use pre encapsulated amalgam instead of mixing their own if amalgam is continued to be used. Pre encapsulated amalgam eliminates the need for elemental mercury in the dentist's office and the spills and dangers associated with elemental mercury. [82]

Household products, including thermometers and contact lens solutions, are responsible for approximately $9 \%$ of the mercury load and laundry, food waste are also emitting mercury. Some Control strategies are presented below.

Mercury thermometers constitute one of the largest sources of mercury from residents to the environment, some programs are being done to restrict sales of mercury thermometers, or to include other stores, like hardware stores, that sell thermometers, such as kitchen thermometers [83].

\subsubsection{Laundry}

Gray water (water from washing machines, showers, and sinks) from residential and commercial laundries constitutes a significant load of mercury to the environment. However, the sources of the mercury in the gray water have not been identified. Mercury may come from dirt, air deposition, or chemicals applied to cotton or finished clothing. We cannot control the sources of mercury in laundry gray water; it can encourage actions that prevent the mercury-containing gray water from entering the sewer system. Although, gray water systems can divert significant loads of mercury from the sewer system [84].

\subsection{Measures against Pollution from Not Intentionally Use of $\mathbf{H g}^{2+}$}

Combustion of fossil fuels, where $\mathrm{Hg}$ is emitted because of its presence in coal, oil and gas, is an example of not intentionally use of $\mathrm{Hg}^{2+}$. Coal combustion is currently the main source of $\mathrm{Hg}$ pollution, worldwide contributing between 750 and 1500 tons per year. The problem is distant distribution of certain species of $\mathrm{Hg}$ emitted and that different species of $\mathrm{Hg}$ are emitted. A good strategy for reducing emitted $\mathrm{Hg}$ is using flue gas cleaning. One reason is relatively low concentration of $\mathrm{Hg}$ combined with large amounts of material handed. Another is that a combination of different techniques is needed to efficiently capture the difference $\mathrm{Hg}$ species in flue gas. Therefore, all new generation sources using fossil fuels and waste incinerators should be equipped with efficient flue gas cleaning systems at the time of construction.

Finally, five easy things you can do to help prevent mercury pollution and protect yourself [85]:

\section{Buy Mercury -Free}

Choose products that do not contain mercury. Look for digital thermometers and electronic thermostats.

Ask store staff to assist you or contact the manufacturer's toll-free number directly.

Ask your dentist if he or she will employ mercury-free composites for any dental work, and enquire if your insurance company will pay for the mercury-free materials (if not, speak with your employer or insurance company).

Ask your local pharmacy or hardware store to consider phasing-out the sale of mercury-containing products [85].

\section{Discard Products Safely}

Separate mercury-containing products, such as thermometers, thermostats, old paint (pre-1991) and batteries (pre-1995) from regular garbage.

Do not remove mercury switches from products, such as thermostats; it is safer to keep or recycle the product when it is intact.

Take any mercury-containing products that you have collected to your local household hazardous waste depot. Call your local municipality for information on where to bring mercury-containing waste. Be careful to ensure that mercury thermometers are well protected from breakage.

\section{Conserve Energy}

Turn the heat back and use air conditioning only when necessary in order to conserve energy. An electronic programmable thermostat can help do this for you.

Purchase only energy-efficient products, such as compact fluorescent lights (instead of incandescent bulbs). Even 
though fluorescents contain a small amount of mercury, they will help reduce energy use and related pollution.

Ensure your home is properly sealed and well-insulated.

\section{Avoid Exposure to Mercury at home, school and work}

Never play with liquid mercury. If you come into contact with liquid mercury, wash the affected area immediately.

Do not vacuum liquid mercury spills. If mercury spills in your home or property, carefully collect the mercury using a damp paper towel and place the mercury and all contaminated waste in a sealed container.

Contact your local pollution control agency if the spill is serious or if you are unable to collect or contain the mercury.

Notify your employer or school official if you see stored or spilled mercury.

\section{Be aware of mercury in fish}

Pregnant women, breastfeeding women and children (under 15) should never consume large ocean fish, especially fresh tuna, shark, swordfish, king mackerel or tile fish. Other fish species should be consumed in moderation.

If you consume freshwater fish frequently, you should know the local fish advisory guidelines and follow them carefully. Pregnant women, breastfeeding women and children (under 15) should avoid large freshwater fish, especially pike, walleye (pickerel), largemouth bass and muskellunge. As a general rule, smaller fish are safer to eat.

Continue to eat fish, while following health guidelines and fish advisories. Catfish (farmed), haddock, trout (farmed), salmon (wild Pacific) and flounder are examples of fish that typically have lower mercury levels.

\section{REFERENCES}

[1] Madison Declaration On Mercury Pollution, 2007. Ambio 36, 62-65.

[2] R.Roncheti, M.Zuurbier, M.Jesenak, J.G. Koppe, U. F. Ahmed, S. Ceccatelli, \& M.P.Villa, Acta Pædiatrica, 2006; 95 Suppl 453: 36_44

[3] K.Leopolda, M. Foulkesb, P. Worsfold; Analytica Chimica Acta 663 (2010) 127-138.

[4] SCOOP, Report of Task 3.2.11: Assessment of the dietary exposure to arsenic, cadmium, lead and mercury of the population of the EU Member States, March 2004. URL: www.mhlw.go.jp/shingi/2004/08/dl/s0817-2k2.pdf.

[5] Food \& Agriculture Organization (FAO) and World Health Organization (WHO), Joint FAO/WHO, Expert Committee on Food Additives, June 2003, ftp://ftp.fao.org/es/esn/jecfa/j ecfa61sc.pdf.

[6] Commission of the European Communities. Communication from the Commission to the Council and the European Parliament on Community Strategy Concerning Mercury. SEC (2005): 101-COM (2005); 20 final. URL: www.europa. eu.int/eur-lex/lex/LexUriServ/LexUriServ.do?uri_CELEX: 52005DC0020:EN:HTML.

[7] L.D.Hylanderand and M.E.Goodsite, Environmental costs of mercury pollution. Science of the Total Envi ronment,
368(2006) 352-370.

[8] WHO.http://www.who.int/water_sanitation_health/dwq/guid elines $3 \mathrm{rd} / \mathrm{en} /$.

[9] R.Sebeka,.A.D.Mckenzie, D.S.Forsyth. and H.B.Conacher. Surveyof total mercury in some edible fish (2004).

[10] WHO and International Programme on Chemical Safety.2002GlobalAssessment of the State of Science of EndocrineDisruptors.Docuent WHO /PCS /EDC /02.2. Geneva: WHO and the International Programme on Chemical Safety.

[11] C.Mombeshora, O.Osinbanjo, and S.O.Ajayi.. Pollution studies on Nigerian rivers. The onset of lead pollution of surface water in Ibadan. Environ.Int. 9, (1983) 81-84.

[12] S.A.Bleicher, 1996. "The Mercury-Containing and Rechargeable Battery Management Act of 1996: A New Direction for Recycling." Environment Reporter. Vol. 27. The Bureau of National Affairs, Inc

[13] B.Fishbein. 1997. Extended Product Responsibility: A New Principle for Product-Oriented Pollution Prevention. "Industry Program to Collect and Recycle Nickel-Cadmium (Ni-Cd) Batteries." (1997) pp. 6-1 to 6-32. EPA530-R-97-009.

[14] Mercury-Containing and Rechargeable Battery Management Act. Pub. L. (1996) 104-142.

[15] UTAH STATE BULLETIN OFFICIAL NOTICES OF UTAH STATE GOVERNMENT May 15, 2013, Nancy L. Lancaster, Editor Kenneth A. Hansen, Director Kimberly K. Hood, Executive Director.

[16] S.L. Liu, F.Nadim, C.Perkins, R.J.Carley, G.E.Hoag, Y.Lin, L.Chen. Atmospheric mercury monitoring survey in Beijing, China. Chemosphere 48, (2002) 97-107.

[17] Z.W.Wang, X.S.Zhang, Z.S.Chen, Y.Zhang. Mercury concentrations in sizefractionated airborne particles at urban and suburban sites in Beijing, China. Atmospheric Environment 40, (2006) 2194-2201.

[18] X.M.Zhang,K.L. Luo, X.Z.Sun, J.A.Tan, Y.L.Lu. Mercury in the topsoil and dust of Beijing city. Science of the Total Environment 368 (2006) 713-722.

[19] M.Z.Tan, F.M.Xu, J.Chen, X.L.Zhang, J.Z.Chen. Spatial prediction of heavy metal pollution for soils in peri-urban Beijing, China based on fuzzy set theory. Pedosphere $16(2006) 545-554$.

[20] C.Xi, X.Xinghui, W.Shan, W.Fan, G.Xuejun, Environmental Pollution 158 (2010) 48-54.

[21] I.M.Dale, An unusual case of mercury contamination. Journal of the Society of Occupational Medicine. 35, (1985), 95-97.

[22] K.E.Von.Muhlendahl, Intoxication for mercury spilled on carpets. Lancet, (1990) 1578.

[23] A.S.Omima, A.Aboud, Impact of pollution with lead, mercury and cadmium on the Oreochromis niloticus, 3, (2010).9.

[24] A.Atul, R.Chourpagar, and G.K.Kulkarni, Heavy metal toxicity to a freshwater Barytelphusa cunicularis (westwood) from Arungabard region, Recent Research in Science and Technology. 3, (2011) 01-05.

[25] J.L.Domagalski，C.N.Alpers，D.G.Slotton, T.H.Suchanek, S.M.Ayers.. Mercury and methylmercury concentrations and 
loads in the Cache Creek watershed, California. Sci, Total Environ. 327 (2004). 215-237.

[26] S.Makani; Biochemical and molecular basis of thimerosal-induced apoptosis in T cells: a major role of mitochondrial pathway. Genes and Immunity 3 (2002) 270-278.

[27] D.Baskin, H.Ngo, V.Didenko. Thimerosal induces DNA breaks, capase-3 activation, membrane damage, and cell death in cultured human neurons and fibroblasts. ToxSci Advanced Access published May 28, 2003.

[28] B.Haley. Mercury and Thimerosal Toxicity: A Factor in Autism.

[29] Agency for Toxic Substances and Disease Registry (ATSDR). Toxicological profile for mercury. Atlanta, GA: U.S. Department of Health and Human Services, Public Health Service1999.

[30] F.R.Zahi, S.J.Rizwi, S.K.Haq, R.H.Khan, Lowdose mercury toxicity and humanhealth, Environmental Toxicology and Pharmacology, 20, (2005), 351-360

[31] K.Burke, Y.Chen, B.Li, A.Petrov, P.Joshi, R.F.Berman, et al.Methylmercury elicits rapid inhibition of cell proliferation in the developing brain and decreases cell cycle regulator, cyclin E. Neuro toxicology 27: (2006) 970-81.

[32] Dicicco-Bloom E. Developmental mercury exposure elicits acute hippocampal cell death, reductions in neurogenesis, and severe learning deficits during puberty. J Neurochem 103 (2007) 1968-8.

[33] H.K.Hussein, , O.A.A.Zinadah, H.A.Samie, F.I.Rabey, and Meerasahib.M.F, Environmental assessment of ground water pollutionby heavy metals and bioaccumulation of mercuryresidues in chicken tissues, 10(71), (2011) 1608916100.

[34] J.Vandeven, S.L.McGinnis. An Assessment of Mercury in the Form of Amalgam in Dental Wastewater in the United States. Water, Air and Soil Pollution 164: (2005)349-366. Online at http://www.springerlink.com/content/1538222288239061/.

[35] A. Cain, S. Disch, C. Twaroski, J. Reindl, C. Case. Substance Flow Analysis of Mercury Intentionally Used in Products in the United States. Journal of Industrial Ecology, 11(3), (2007), 61-75.

[36] W.F. Fitzgerald, G.A. Gill, Anal. Chem. 51 (1979) 1714.

[37] T. Labatzke, G. Schlemmer, Anal. Bioanal. Chem. 378 (2004) 1075.

[38] W.A. Telliard, United States Environmental Protection Agency, Federal Register, EPA-821-R-01-033 Method 1631 Revision C, 67, (2001) 209.

[39] European Standard EN 13506, 2001 (RefNrEN 13506:2001).

[40] O. Elsholz, C. Frank, B. Matyschok, F. Steiner, O. Wurl, B. Stachel, H. Reincke,M. Schulze, R. Ebinghaus, M. Hempel, Fresen. J. Anal. Chem. 366 (2) (2000)196-199.

[41] K. Leopold, L. Harwardt, M. Schuster, G. Schlemmer, Talanta 76 (2008)382-388.

[42] O. Wurl, O. Elsholz, R. Ebinghaus, Talanta 52 (2000) 51-57.

[43] J.L. Capelo, I. Lavilla, C. Bendicho, Anal. Chem. 72 (2000)
$4979-4984$.

[44] C. Fernandez, A.C.L. Conceicao, R. Rial-Otero, C. Vaz, J.L. Capelo, Anal. Chem. 78 (2006) 2494-2499.

[45] I.Gil, C.Lavilla, C. Bendicho, Anal. Chem. 78 (2006) $6260-6264$

[46] A.S. Ribeiro, M.A. Vieira, S. Willie, R.E. Sturgeon, Anal. Bioanal. Chem. 388 (2007) 849-857.

[47] A.S. Ribeiro, M.A. Vieira, S. Willie, R.E. Sturgeon, Anal. Bioanal. Chem. 388 (2007) 849-857.

[48] S. Gil, I. Lavilla, C. Bendicho, Spectrochim. Acta Part B 62 (2007) 69-75.

[49] K. Leopold, M. Foulkes, P.J. Worsfold, Anal. Chem. 81 (9) (2009) 3421-3428.

[50] A. Zierhut, K. Leopold, L. Harwardt, P.J. Worsfold, M. Schuster, J. Anal. Atom. Spectrom. 24 (2009) 767-774.

[51] S. Gil, I. Lavilla, C. Bendicho, Anal. Chem. 78 (2006) 6260-6264.

[52] K. Leopold, M. Foulkes, P.J. Worsfold, Anal. Chem. 81 (9) (2009) 3421-3428.

[53] J.H. Pavlish et al. Fuel Processing Technology 82 (2003) 89-165.

[54] J.W. Robinson, Atomic Absorption Spectroscopy, Marcel Dekker Inc., New York, (1966), 204.

[55] M. Slavin, Atomic Absorption Spectroscopy, 2nd ed., Wiley, New York, (1978), 193.

[56] W.J. Price, Spectrochemical Analysis by Atomic Absorption, Heyden \& Son, London, UK, (1979), 392.

[57] A.M. Ure, Anal. Chim. Acta 76 (1975) 1-26.

[58] H. Morita, H. Tanaka, S. Shimomura, Spectrochim. Acta 50B (1995) 69-84.

[59] U.S. Environmental Protection Agency, Method 29-Determination of Metals Emissions from Stationary Sources, U.S. EPA, Emission Measurement Technical Information Center, TM-029, April 25, 1996.

[60] SIS, Luftunderso"knigar- Utsläpp till luft- Besta"mning av totalkvicksilverhalten med flamlo"s atomabsorptionsmetod (Air quality- stationary source emissions- determination of the total mass concentration of mercury- flameless atomic absorption methods), SS 0284 23, Stockholm, Sweden, Standardiseringskommissionen i Sverige, 1991, Dec., p. 11, in Swedish.

[61] American Public Health Association, Standard Methods for the Examination of Water and Wastewater, 15th ed., American Public Health Association, Washington, DC, 1980.

[62] U.S. Environmental Protection Agency, Methods of Chemical Analysis of Water and Wastes, U.S. Environmental Protection Agency, Cincinnati, OH, 1983, EPA-600/4-82-05.

[63] U.S. Environmental Protection Agency, Test Methods for Evaluating Solid Waste: Physical/Chemical Methods, 3rd ed., U.S. Environmental Protection Agency, Washington, DC, 1988, Sept, SW-846.

[64] J.H. Pavlish, et al., Center for Air Toxic Metals Final 
Technical Report, Energy and Environmental Research Center: Grand Forks, North Dakota, 3, (2000).

[65] EPRI, Evaluation of Methods for Analysis of Mercury and Chlorine in Coal, EPRI. 1000287, (2000).

[66] P. Chu, N. Goodman, G. Behrens, R. Roberson, Total and speciated mercury emissions from U.S. coalfired power plants, Proceedings of the Air Quality II: Mercury, Trace Elements, and Particulate Matter Conference, McLean, VA, Sept Paper A34, 2000, 19-21.

[67] I. Olmez, M. Ames, N.K. Aras, Presented at the Annual Meeting of the American Nuclear Society, San Diego, CA, 1993, June.

[68] I. Olmez, X. Huang, M.R. Ames, Presented at the 88th Annual Meeting and Exhibition of the Air and Waste Management Association, San Antonio, TX,Paper 95-MP21.02, (1995).

[69] L.J. Blanchard, J.D. Robertson, Determination of mercury in coal using radiochemical methods, Analysis 122 (1997) $1261-1264$.

[70] R. Dams, Pure Appl. Chem. 64 (1992) 991- 1014.

[71] SVTC. Just say no to e-waste: background document on hazards and waste from computers; 2005 (June). http://www.svtc.org/cleancc/ pubs/sayno.htm.

[72] Electronic Industries Alliance. Consumer product mercury information sheet; 2005 (June). http://www.eiae.org/chemica 1s/files/CEI mercury.pdf.

[73] Randall PM. Mercury reduction in products and processes: a review of the electrical and electronic industries. Environ Prog 1995;14:232-9.

[74] Lee S, Akao T, Kiryakov N, Suematsu H, Yamauchi H.
Development of Hg-containing superconductors: from precursors to materials prototypes. Physica C 2000;338:60-6.

[75] Jang YC, Townsend TG. Leaching of lead from computer printed wire boards and cathode ray tubes by municipal solid waste landfill leachates. Environ Sci Technol 37: 2003; 4778-84.

[76] Electronic Industries Alliance. Consumer product mercury information sheet; 2005 (June). http://www.eiae.org/chemicals/files/CEI_mercury.pdf

[77] Randall PM. Mercury reduction in products and processes: a review of the electrical and electronic industries. Environ Prog14 (1995); 232-9.

[78] G.Howland, T.Bender, L.Hayes. Mercury measurement in Canada: domestic and global dimensions. In: Parsons MB, Percival JB, editors. Mercury: Sources, Measurements, Cycles, and Effects, 34 :(2005), 14-15.

[79] Mineralogical Association of Canada; Nova Scotia, Canada, (2005) 287-97.

[80] http://www.ce.org/publications/books_references/5tech_Wat ch-2005.pdf

[81] A.Esmaeili Sari, E.Abdollah Zadeh, S.Jurabian Shshtari, S.M.Ghasempour, J.Fasa Medical Science, 2011, 1, 24.

[82] Western Lake Superior Sanitary District, et. al. Blueprint for Mercury Elimination. 1997.

[83] Moran.K, Palo Alto RWQCP. Personal communication with Ashli Cooper, September 4, 199.

[84] L.Walker Associates. Residential Metals Study. Prepared for Contra Costa County Sanitary District. 1994.

[85] http://www.zyra.org.uk/. 